\title{
Deformation-Induced Color Changes in Mechanochromic Polyethylene Blends
}

Brent R. Crenshaw, Mark Burnworth, Devang Khariwala, Anne Hiltner, Patrick T. Mather, Robert Simha, and Christoph Weder*

Department of Macromolecular Science and Engineering, Case Western Reserve University, 2100 Adelbert Road, Cleveland, Ohio 44106-7202

\section{Supporting Information}

a

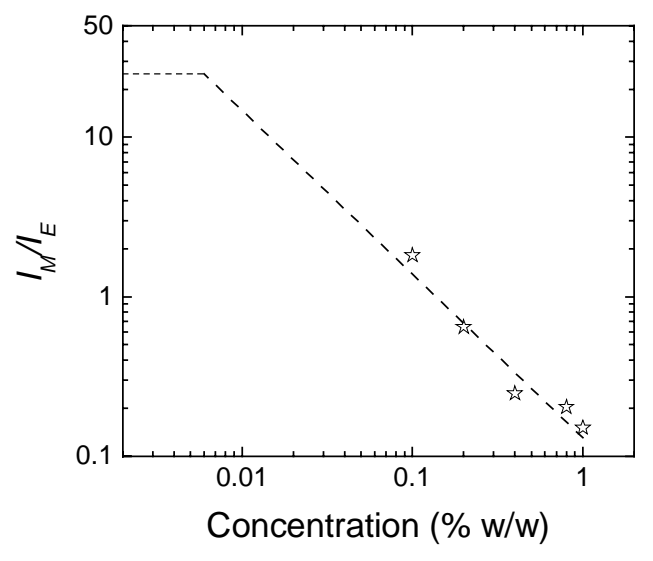

b

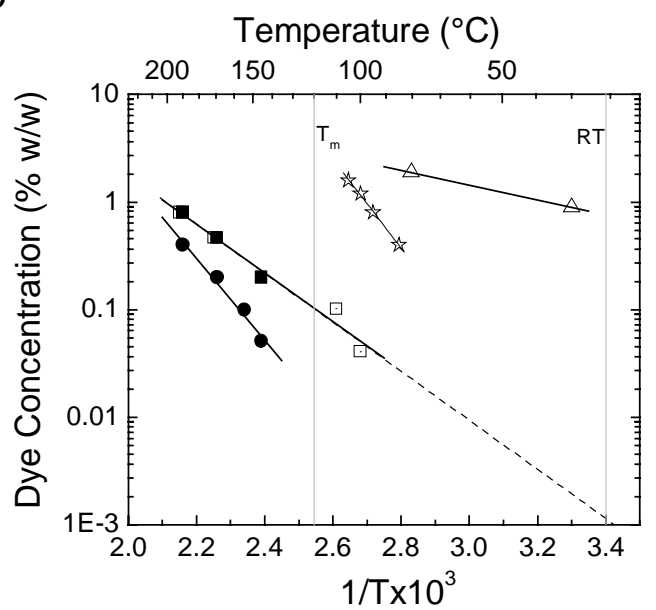

Figure S1: a) $I_{M} / I_{E}$ of PE94/C18-RG blends plotted against log concentration. Dashed line is an extrapolation to $I_{M} / I_{E}=25(\bullet)$ b) Solubility of C62-RG ( $\left.\rho\right), \operatorname{C18}-\mathbf{R G}(\bullet), \mathbf{C 1 - R G}(\mathbf{\square}, \square)$ and $\mathrm{C} 1-\mathrm{YB}(\bullet)$ in LLDPE. 
a

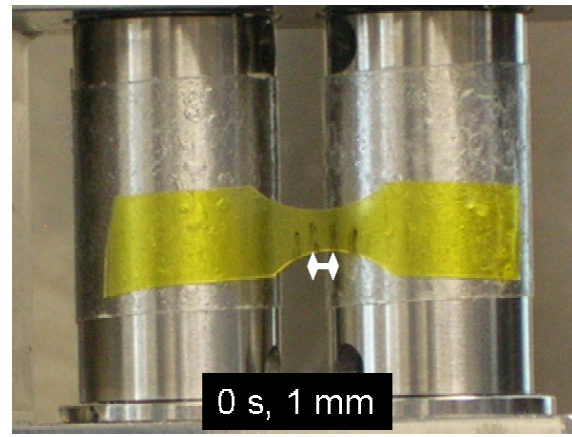

C

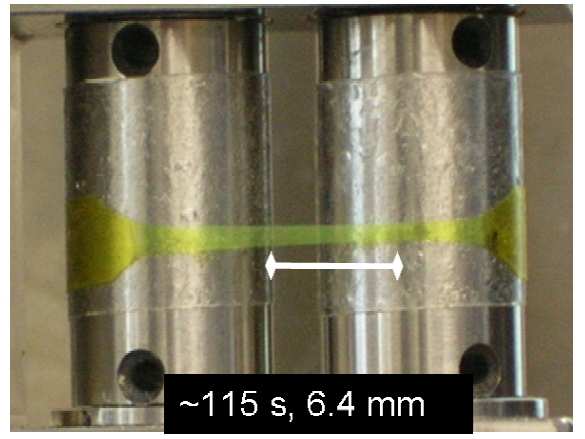

e

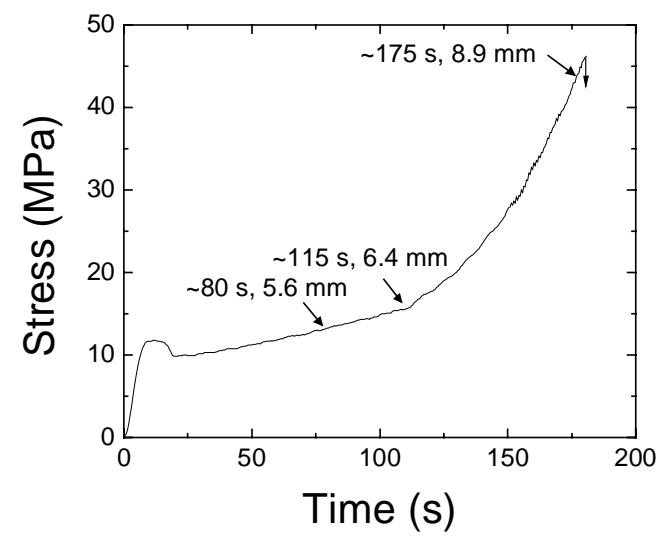

b

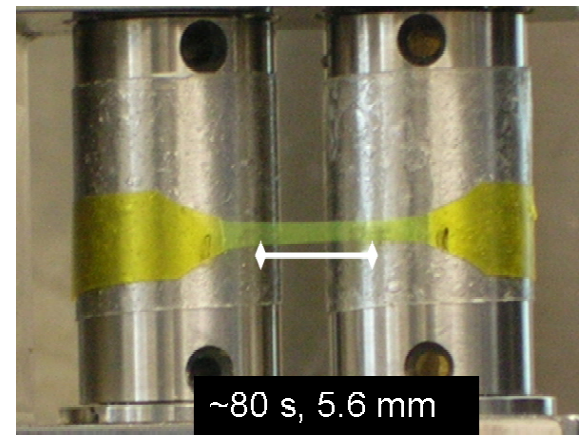

d

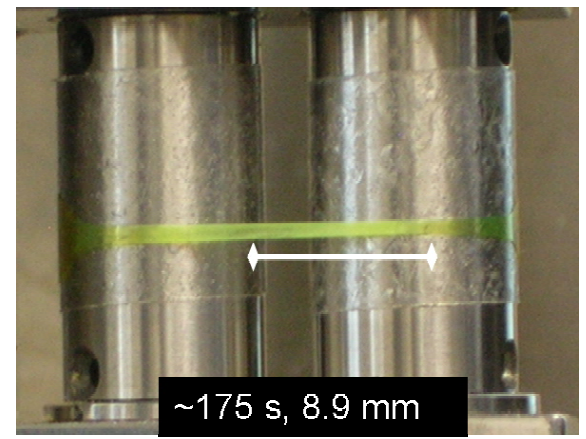

f

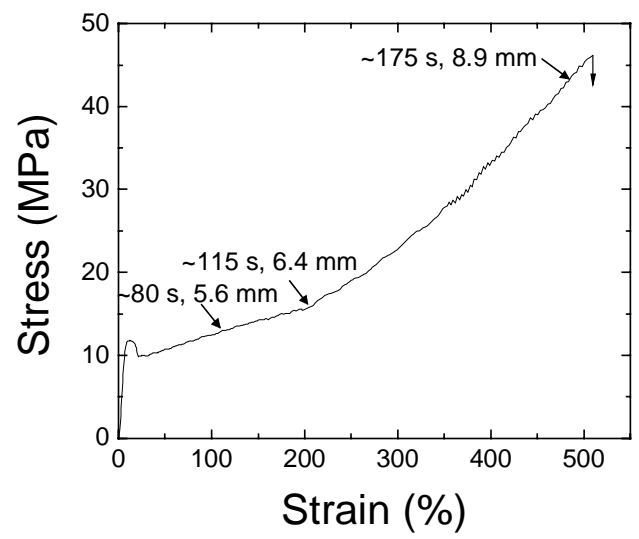

Figure S2. Pictures and graphs illustrating the development of strain during tensile experiments performed on PE samples and explaining the artificially low strains reported in the paper. In this setup, strain is confined to the distance between the two rotating columns. The strain recorded by the instrument is calculated (as per Sentmanat, M. L. Rheol. Acta 2004, 43,657$)$ by this distance $(12.72 \mathrm{~mm})$ and the strain rate $\left(0.01 \mathrm{~s}^{-1}\right.$, e $)$ and is reported as 
'Strain (\%)' in (f). The actual strain on the sample has be obtained by measuring the displacement of ink marks on the sample, initially placed $1 \mathrm{~mm}$ apart (a). Upon necking the actual strain increases to $\sim 460 \%$ (b). by the time the neck propagates to the edge of the strain region, the recorded strain is only $200 \%$, but the actual strain is $540 \%$ (c). The strain hardening regime begins at this point and the increase in recorded strain is consistent with the increase in actual strain until break (d). 